\title{
A FORMAÇÃO DE PROFESSORES COMO ESTRATÉGIA DE CONSOLIDAÇÃO DA HEGEMONIA DO CAPITAL
}

\author{
Wildiana Kátia Monteiro Jovino ${ }^{1}$
}

\section{Resumo}

O presente trabalho inicia a discussão acerca dos elementos fundamentais à compreensão do papel específico que a educação assume na sustentação ideológica da ordem social do capital, evidenciando a repercussão desse processo na formação de professores para a educação básica. Como veremos, a doutrina neoliberal, redefinida na chamada Terceira Via, ou, ainda, social-liberalismo, traça sua hegemonia através de um conjunto ampliado de reformas com o objetivo de garantir os interesses do grande capital sobre a justiça social. O caráter expansionista, destrutivo e incontrolável do metabolismo social no capitalismo engendra uma "crise estrutural" que evidencia, de forma contundente, os antagonismos e as desigualdades que assolam a vida humana: o crescimento das taxas de desemprego, a crise ambiental e a explosão da barbárie social são os ingredientes da gestão econômica que atacam cruelmente o trabalho humano, com diferentes métodos de organização do trabalho, tais como o taylorismo/fordismo, e, atualmente, o toyotismo. O emprego das formas de produção flexível, da inovação científico-tecnológica e de novos modelos de gerenciamento da organização do trabalho, apresenta grande demanda social à educação escolar, uma vez que assume papel decisivo na construção da "nova" escola. Ao Estado, cabe o fomento à política de formação para prover a mão de obra necessária ao padrão de produção e legitimar o arcabouço de sustentação dos interesses corporativos oportunistas do mercado que defendem um tipo de crescimento que encurta o conceito de cidadania. O conjunto desses fatores abre caminho à expansão da educação a distância como modalidade preferencial para a formação de professores e demarca um processo de grandes mudanças para a organização do trabalho pedagógico e dos sistemas de ensino.

Palavras-chave: Formação de professores. Educação. Educação a distância.

\section{TEACHER TRAINING AS A STRATEGY FOR CONSOLIDATION OF CAPITAL'S HEGEMONY}

\begin{abstract}
The present work evaluates the discussion about fundamental elements to the understanding of the specific role that education assumes in the ideological support of the social order of capital, offering evidence of the repercussion of this process in the formation of teachers for basic education. As we will see, the neoliberal doctrine, redefined in the so-called Third Way, or yet social-liberalism, traces its hegemony through an expanded set of reforms aimed at securing the interests of the great capital over social justice. The expansionist, destructive and uncontrollable character of social metabolism in capitalism engenders a "structural crisis" that strongly demonstrates the antagonisms and inequalities that afflict human life: rising unemployment rates, the environmental crisis and the explosion of social backwardness are the ingredients of economic management that cruelly attack human labor, with different
\end{abstract}

\footnotetext{
${ }^{1}$ Prof ${ }^{a}$ Dra. da Universidade Aberta do Brasil (UECE/UAB) e da Prefeitura Municipal de Fortaleza. E-mail: wjovino@gmail.com.
} 
methods of work organization, such as Taylorism/Fordism, and now Toyotism. The use of flexible forms of production, scientific-technological innovation and new management models of work organization presents a great social demand for school education since it plays a decisive role in the construction of the "new" school. To the state is assigned the role of fomenting training policies to provide the necessary labor to fit production standards and to legitimize the support framework of the opportunist corporate interests of the market that aims at a type of growth that shortens the concept of citizenship. The set of these factors opens the way for the expansion of distance learning as a preferred form for teacher training and marks a process of great changes for the organization of pedagogical work and education systems.

Keywords: Teacher training, Education, Distance education.

Nesse texto, inicio a discussão acerca de algumas políticas públicas brasileiras destinadas à formação inicial e continuada de professores e as implicações teóricas e práticas dessa agenda para essa classe trabalhadora. Proponho o exame crítico dos elementos fundamentais à compreensão da natureza da educação, em seu sentido estrito, e do papel específico que assume na sustentação ideológica da ordem social do capital, haja vista o seu caráter não determinante na transformação radical das relações sociais. Cabe esclarecer que a educação, por si só, não é capaz de modificar as relações de produção. Ela não cria as circunstâncias, ou seja, ela não transforma o real nem opera a construção de uma nova materialidade, ou seja, a prática subjetiva, isolada, se inscreve numa percepção meramente contemplativa da realidade, isto é, numa atividade que não se objetiva. Lembro aqui Marx (1976), com a terceira das Teses contra Feuerbach, quando justamente critica a percepção da realidade "só de um ponto de vista subjetivo", através de crenças que pregam a transformação dos seres humanos mediante uma "educação mudada", lembra que "o próprio educador deve ser educado".

A doutrina neoliberal, redefinida na chamada Terceira Via, ou, ainda, socialliberalismo $^{2}$, traça sua hegemonia através de um conjunto ampliado de reformas para garantir os interesses do grande capital sobre a justiça social. A crise de acumulação, que se instaura na sociedade regida pela lógica do capital, sobreleva o caráter expansionista, destrutivo e

\footnotetext{
${ }^{2}$ Denominado de Terceira via, centro radical, centro-esquerda, nova-esquerda, nova social-democracia, socialdemocracia-modernizadora ou governança progressiva, esse projeto - direcionado, principalmente, às forças sociais de centro esquerda que chegaram ao poder nos últimos anos do século XX ou que lutam intensamente para isso - parte das questões centrais do neoliberalismo para refiná-lo e torná-lo mais compatível com sua própria base e princípios constitutivos, valendo-se de algumas experiências concretas desenvolvidas por governos de países europeus. Cf. LIMA Kátia R. de S.; MARTINS, André Silva. A nova pedagogia da hegemonia: pressupostos, princípios e estratégias. In: NEVES, Lúcia M. W. (Org). A nova pegagogia da hegemonia: estratégias do capital para educar o consenso. São Paulo: Xamã, 2005, 41-67, p. 43.
}

\begin{tabular}{|l|l|l|l|l|}
\hline Gonista Qialectus & Ano 4 & n. 10 & Janeiro - Julho 2017 & p. 115-126 \\
\hline
\end{tabular}


incontrolável do metabolismo social em uma "crise estrutural" que evidencia, de forma contundente, os antagonismos e as desigualdades que assolam a vida humana: o crescimento das taxas de desemprego, a crise ambiental e a explosão da barbárie social são os ingredientes da gestão econômica do capital que atacam cruelmente o trabalho humano. (MÉSZÁROS, 2009a, 2009b).

No plano político, a reprodução ampliada do capital exige a intervenção do Estado não somente nas formas de organização do trabalho, mas no desenrolar das relações sociais, visando ao aumento da produtividade e à construção do consenso em torno dos valores burgueses. Perseguindo tal objetivo, a burguesia brasileira redefine sua relação com os aparelhos da sociedade civil utilizando-se de uma "pedagogia da hegemonia" para servir aos interesses do grande capital. (NEVES, 2005).

A instituição escolar tem, nesse sentido, um papel importante, específico, no sistema de internalização que alimenta os processos sociais mais "abrangentes de reprodução intimamente interligados". Os "códigos culturais" da dita "sociedade do conhecimento"3 exigem o desenvolvimento de indivíduos competentes, flexíveis, polivalentes e hábeis para o desenvolvimento de tarefas, assim como uma subjetividade peculiar, avessa à percepção da totalidade intrínseca aos processos sociais e receptiva à visão da vida social como uma sobreposição de fragmentos significativos somente a partir do viés custo/benefício.

O despontar da educação como a "chave" para o desenvolvimento mundial e como o antídoto para as mazelas oriundas do desemprego e da pobreza delineia-se mais claramente no cenário da chamada globalização econômica. A UNESCO, agência das Nações Unidas responsável pela educação, sob o comando do Banco Mundial, "o ministério mundial da educação dos países periféricos”, como foi denominado por Leher (1999), conduz diversas orientações internacionais ${ }^{4}$ para pactuar um acordo mundial pelo desenvolvimento através da educação escolar.

Em face dessas demandas, especialmente a partir da década de 1990, somando adeptos ao projeto de realinhamento dos diferentes segmentos aos tempos da qualidade total e do

3 A ideologia da sociedade do conhecimento, segundo Duarte, desempenha uma função específica na sociedade capitalista contemporânea, qual seja, a de enfraquecer as críticas radicais ao capitalismo e às lutas por sua superação. Cf. DUARTE, Newton. Sociedade do conhecimento ou sociedade das ilusões?: quatro ensaios críticos-dialéticos em Filosofia da Educação. Campinas, SP: Autores Associados, 2003, p. 13-14.

${ }^{4}$ Este período inaugura-se com a Conferência Mundial de Jomtien, realizada na Tailândia, que produziu o documento que deveria ser seguido por todos os países-membros periféricos: Declaração mundial sobre educação para todos e o plano de ação para satisfazer as necessidades básicas de aprendizagem. Cf. UNESCO. Declaração mundial sobre educação para todos: satisfação das necessidades básicas de aprendizagem. Jomtien, Tailândia, 1990.

\begin{tabular}{|l|l|l|l|l|}
\hline Q Povista Qialectus & Ano 4 & n. 10 & Janeiro - Julho 2017 & p. 115-126 \\
\hline
\end{tabular}


método do mercado e amparado por avaliações internacionais e nacionais, o discurso dominante atesta o baixo rendimento escolar, a qualidade deficiente do ensino, a formação ineficaz dos professores, a escassez e a má gestão dos recursos do sistema educacional. Tais argumentos associam a estagnação da empregabilidade dos indivíduos e o entrave do desenvolvimento econômico do país à ineficiência da educação brasileira.

No Brasil, as reformas que dão materialidade e embasam essa mudança na esfera educacional ganham maior repercussão com a Lei de Diretrizes e Bases da Educação Nacional (LDB), $\mathrm{n}^{\circ}$ 9.394/1996 , ou Lei Darcy Ribeiro, como ficou popularmente conhecida. Após longos anos de embates entre os estratos que detinham o poder econômico e político e os grupos organizados da educação ${ }^{6}$, a referida lei é aprovada, consagrando o pragmatismo neoliberal para o sistema educacional nacional.

A nova LBD, nos marcos da pretendida formação de cidadãos eficientes, competitivos, flexíveis, produtivos, empregáveis e consumidores, consolida um intenso processo de "ressignificação" do fazer docente, mediante a defesa de paradigmas curriculares e pedagógicos. A pedagogia do "aprender a aprender", que sugere uma superação do que se convencionou chamar de pedagogia tradicional, prioriza não mais a aquisição de conteúdos, entendidos como "enciclopédicos", mas a capacidade de aprender e desenvolver competências capazes de mobilizar saberes, valores e decisões adequadas a cada situação particular. Para essa pedagogia, o importante é adquirir um conjunto básico de habilidades indispensáveis ao enfrentamento das severas exigências do mercado de trabalho e da competitividade entre os indivíduos. Avaliando criticamente o modelo, Duarte completa:

[...] Quando educadores e psicólogos apresentam o "aprender a aprender" como síntese de uma educação destinada a formar indivíduos criativos, é importante atentar para um detalhe fundamental: essa criatividade não deve ser confundida com busca de transformações radicais na realidade social, busca de superação radical da sociedade capitalista, mas sim criatividade em termos de capacidade de encontrar novas formas de ação que permitam melhor adaptação dos indivíduos aos ditames da sociedade capitalista. (DUARTE, 2003, p. 12).

\footnotetext{
${ }^{5}$ BRASIL. Ministério da Educação. Lei no 93.94, de 20 de dezembro de 1996. Estabelece as diretrizes e bases da educação nacional. Brasília, 1996.

6 Nas várias versões de Substitutivo elaboradas pelo primeiro Relator da matéria, Deputado Jorge Hage, levou-se em consideração as inúmeras sugestões advindas das audiências públicas ao longo dos anos 1989 e 1990 , bem como dos grupos organizados, em especial o Fórum em Defesa da Escola Pública, que reuniu diversas instituições representativas dos segmentos organizados da educação nacional, em todos os seus níveis. Para maior detalhamento, ver também: SAVANI, Dermeval. A nova lei da educação: trajetória, limites e perspectivas. 4. ed. Campinas, SP: Autores Associados, 1998.
}

\begin{tabular}{|c|c|c|c|c|}
\hline Q Povista Dinlectus & Ano 4 & n. 10 & Janeiro - Julho 2017 & p. $115-126$ \\
\hline
\end{tabular}


Diante do grande déficit histórico relativo à educação brasileira, as políticas voltadas à formação de professores também acumulam a indiferença e o descaso até o início do século $\mathrm{XX}$, quando a chamada política de "modernização conservadora" imprimiu força a muitas transformações na sociedade brasileira, uma vez que focou na ampliação dos espaços para a acumulação do capital e na construção dos alicerces do capitalismo financeiro (dependente). (SAVIANI, 2007).

Do "entusiasmo pela educação", característico dos primeiros anos da República brasileira que se mobiliza a favor da "instrução" das massas analfabetas ${ }^{7}$ para fomentar a produção, o consumo e as mudanças político-eleitorais, ao “otimismo pedagógico" dos escolanovistas, um ciclo de reformas educacionais prescreve importantes referências para a formação de professores. As Escolas Normais, de nível médio, surgem para preparar professores para o magistério primário, até então uma ocupação associada à imagem feminina e, talvez por isso, desvalorizada pelo caráter maternal e abnegada associada ao seu exercício.

Entre as décadas de 1960-70, quando a crise da acumulação capitalista dimensiona a transformação do sistema produtivo em diferentes métodos de organização do trabalho, tais como o taylorismo/fordismo, e, atualmente, o toyotismo, o emprego das formas de produção flexíveis, da inovação científico-tecnológica e de novos modos de gerenciamento da organização do trabalho apresenta nova demanda social à educação escolar que prontamente se prepara para prover a mão de obra necessária ao padrão de produção.

Nesse processo de reestruturação do capital, a "teoria do capital humano" "8 é a ideologia predominante entre os economistas e intelectuais, mobilizando a ascensão da "pedagogia tecnicista", de forma que os princípios da racionalidade, eficiência e produtividade passam a direcionar a reorganização das escolas, o processo ensinoaprendizagem e o papel do professor, unificando os padrões e a especialização das funções.

Sobre isto, Saviani (2007) sintetiza:

Se na pedagogia tradicional a iniciativa cabia ao professor, que era, ao mesmo tempo, o sujeito do processo, o elemento decisivo e decisório;

7 Em 1920, 75\% da população brasileira eram analfabetas e o voto era proibido a este público. Cf. GUIRALDELLI JR, Paulo. História da educação. 2. ed. São Paulo: Cortez, 1992, p. 18.

${ }^{8}$ A idéia-chave da teoria do capital humano, de Theodore Schultz, defende que a cada conjunto de determinado volume de instrução, treinamento e habilidades adquiridas, potencializa-se a capacidade de trabalho e de produção, sendo, por isso, um investimento rentável no plano geral do desenvolvimento das nações e na mobilidade dos indivíduos. FRIGOTTO, Gaudêncio. Educação e crise no capitalismo. São Paulo, Cortez, 2003.2003, p. 41.

\begin{tabular}{|l|l|l|l|l|}
\hline Renista Dialectus & Ano 4 & n. 10 & Janeiro-Julho 2017 & p. 115-126 \\
\hline
\end{tabular}


e se na pedagogia nova a iniciativa se desloca para o aluno, situandose o nervo da ação educativa na relação professor-aluno, portanto, relação interpessoal, intersubjetiva; na pedagogia tecnicista o elemento principal passa a ser a organização racional dos meios, ocupando o professor e o aluno posição secundária, relegados que são à condição de executores de um processo cuja concepção, planejamento, coordenação e controle ficam a cargo de especialistas supostamente habilitados, neutros, objetivos, imparciais. A organização do processo converte-se na garantia da eficiência, compensando e corrigindo as deficiências do professor e maximizado os efeitos de sua intervenção. (SAVIANI, 2007, p. 380).

$\mathrm{Na}$ sequência, o clima cultural do final do século, chamado por alguns de "pósmoderno", dá novo tom aos comportamentos. É quando se anuncia a "revolução informática" e o desgaste geral do ideal moderno, o declínio das narrativas libertárias e a desqualificação do conhecimento historicamente acumulado. Seus adeptos se arvoram na revisão das teorias críticas e na redefiniçãa dos princípios filosóficos, sociológicos, políticos e educacionais, com o objetivo de liberá-los das teorias explicativas de caráter totalizante, mediante a construção de padrões teóricos mais adequados aos reclames da "nova era".

A súplica é pela deslegitimação, fragmentação e dissolução do sujeito social. Seu ceticismo diante de toda prescrição universalizante, de pretensão basilar e atemporal para a ação racional e coletiva, traz, contudo, consequências nada desprezíveis para a formação e prática docentes. Quando seus ideólogos decretam a falência de todos os discursos totalizantes, das filosofias explicativas, dos valores morais, sobretudo os cristãos, das instituições e das esperanças no devir, projeta-se também a banalidade cotidiana, o individualismo e o consumismo como inspiração para o homem contemporâneo.

Nessa perspectiva, Lyotard (2009) apresenta a vocação do cenário pós-moderno, que é essencialmente "cibernético-informático e informacional”. Isso impulsiona especial interesse por estudos sobre linguagem, "inteligência artificial", estrutura e funcionamento do cérebro, que assumem a prioridade nas pesquisas acadêmicas e financiamentos governamentais. $\mathrm{Na}$ abordagem, o conhecimento científico, considerado insuficiente para explicar e justificar os fenômenos sociais, deve limitar-se a uma informação de certo tipo, o bit, compatível com as “máquinas informacionais". Impõe-se à ciência o selo de um tipo especial de mercadoria, uma "tecnologia intelectual” a serviço dos interesses do capital e do Estado.

\begin{tabular}{|c|c|c|c|c|}
\hline Rovista Dialectus & Ano 4 & n. 10 & Janeiro - Julho 2017 & p. $115-126$ \\
\hline
\end{tabular}


Na hegemonia da informática ${ }^{9}$, o conhecimento perde a sua condição de valor de uso e é "produzido" para ser "vendido". O saber, assim, assume um valor específico, que se realiza somente por meio da "troca", tornando-se a moeda corrente na disposição que assume na sociedade chamada "pós-industrial". Nesse sentido, o conhecimento se desvencilha da "realização da ideia" ou da "emancipação dos homens", subordinando-se ao "essencial do transmissível" e ao critério do "vendável". O conhecimento (o imaterial), e não o trabalho vivo (o material), torna-se a nova força de produção. (LYOTARD, 2009, p. 89).

Nesse contexto, as reformas relativas à formação dos professores, não somente no Brasil, mas em outros países, inserem-se numa corrente que defende a "renovação" das práticas e da formação, levando em conta os seus "saberes"10 e as práticas de seu trabalho cotidiano. Com o aporte de renomados intelectuais e políticos, a "epistemologia da prática

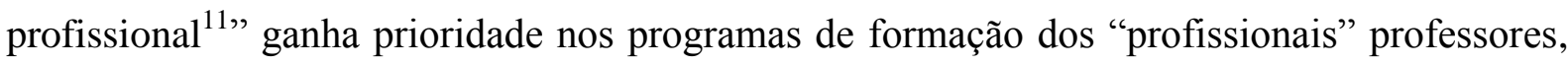
haja vista o sentimento de incerteza que paira no presente dito "efêmero" e a suposta impossibilidade da "teoria" em desnudá-la.

A concepção, baseada nos estudos desenvolvidos pelo pedagogo estadunidense Donald Shön, este fundamentado no pensamento de John Dewey, reconfigura o construtivismo e propõe mudanças substanciais na relação entre a teoria e a prática na construção do pensamento e da formação do professor, seja ela na forma inicial ou continuada, uma vez que atribui uma suposta relação de distanciamento entre os "saberes profissionais" e os “conhecimentos universitários". Pauta-se, portanto, numa relação que concede caráter acessório ao conhecimento científico/teórico/acadêmico e uma supervalorização da prática realizada pelos professores na escola e na sala de aula.

De acordo com essa perspectiva, a "prática profissional ganha realidade própria, independente dos constructos teóricos dos pesquisadores e de procedimentos elaborados por

\footnotetext{
${ }^{9}$ Esclareço que não é o caso imprimir um julgamento de valor acerca do uso da tecnologia, pois cairíamos num modo grosseiro de negação da capacidade ininterrupta da consciência humana de produzir o novo. Entendo, contudo, que o desenvolvimento da ciência e da tecnologia não se rege por uma lógica autônoma. A rigor, elas têm por base o conjunto dòs fenômenos históricos que permitiram o desenvolvimento das forças produtivas. Destaco, outrossim, que a hegemonia da informática na contemporaneidade firma compromisso, antes, com a expansão do capital e traz consigo um conjunto de prescrições que são indistintamente aceitos pelos indivíduos como indispensáveis à sua inclusão e ao seu reconhecimento na sociedade, silenciando a crítica acerca das desigualdades sociais.

${ }^{10}$ Para Tardif (2002), o conceito de saberes engloba o conjunto dos conhecimentos, competências e habilidades que nossa sociedade julga suficientemente úteis ou importantes para inseri-los em processos de formação institucionalizados. Cf. TARDIF, Maurice. Saberes docentes e formação profissional. Petrópolis, RJ: Vozes, 2002, p. 295.

${ }^{11}$ Tardif (2002) chama de epistemologia da prática profissional o estudo do conjunto dos saberes utilizados realmente pelos profissionais em seu espaço de trabalho cotidiano para desempenhar todas as suas tarefas. (IDEM, p. 255, grifos do autor).
}

\begin{tabular}{|l|l|l|l|l|}
\hline Q Povista Qialectus & Ano 4 & n. 10 & Janeiro - Julho 2017 & p. 115-126 \\
\hline
\end{tabular}


tecnólogos da ação. Nesse sentido, a prática constitui um lugar de "aprendizagem autônoma e imprescindível". (TARDIF, 2002, p. 288). Em defesa da dita "relação de exterioridade", estabelecida entre os professores e os "saberes da formação profissional", transmitidos pelas universidades, o autor ainda alega que:

Essa distância [entre os saberes profissionais e os conhecimentos universitários] pode assumir diversas formas, podendo ir da ruptura à rejeição teórica pelos profissionais, ou então assumir formas mais atenuadas como adaptações, transformações, seleção de certos conhecimentos universitários a fim de incorporá-los à prática. Desse ponto de vista, a prática profissional nunca é um espaço de aplicação dos conhecimentos universitários. Ela é, na melhor das hipóteses, um processo de filtração que os dilui e os transforma em função das exigências do trabalho; ela é, na pior das hipóteses, um muro contra o qual vêm se jogar e morrer conhecimentos universitários considerados inúteis, sem relação com a realidade do trabalho diário docente nem com os contextos concretos de exercício da função docente. (TARDIF, 2002, p. 257).

A ampla defesa pela incorporação das "práticas cotidianas" e da "subjetividade dos professores", seus "saberes práticos" e suas "histórias de vida" como referência central dos programas de formação, revela-nos a percepção fragmentada e o caráter pragmático que tem orientado a educação brasileira. Nesta perspectiva, a qualidade e a quantidade do conhecimento devem ser ditadas unicamente por sua relevância para a resolução dos problemas da vida prática e de acordo com as características da clientela e da região. (MELLO, 2004). Desse caráter instrumental conferido aos pressupostos educativos, sobrelevam-se a ruptura de identidades, tanto das instituições escolares, como do trabalho docente.

A tendência "idealista da educação" nacional crê na superação de "mentalidades errôneas", causadoras dos problemas sociais, pela difusão de novas ideias entre os indivíduos, através da educação. Cabe lembrar que o predomínio do trabalho morto sobre o vivo na ordem econômica torna especialmente descartável a mercadoria humana e patenteia, na esfera educacional, o movimento que Saviani classifica como a "pedagogia da exclusão":

Trata-se de preparar os indivíduos para mediante sucessivos cursos dos mais diferentes tipos, se tornarem cada vez mais empregáveis, visando a escapar da condição de excluídos. E, caso não o consigam, a pedagogia da exclusão lhes terá ensinado a introjetar a responsabilidade por essa condição. Com efeito, além do emprego

\begin{tabular}{|l|l|l|l|l|}
\hline Q Poxista Qialectus & Ano 4 & n. 10 & Janeiro - Julho 2017 & p. 115-126 \\
\hline
\end{tabular}


formal, acena-se com a possibilidade de sua transformação em microempresário, com a informalidade, o trabalho por conta própria, isto é, sua conversão em empresário de si mesmo. (SAVIANI, 2007, p. 429).

Para apimentar esse cenário, o desenvolvimento das tecnologias da informação e comunicação (TICs) dissemina transformações na economia, na política, nas relações sociais e culturais. Elas impulsionam também um tipo especial de competição para a conquista de um maior volume de mercadorias e lucros entre as empresas e organizações, ao mesmo tempo em que surgem novas demandas para a escola, que são atropeladas pelo surgimento de "um novo tipo de sociedade do conhecimento" (MELLO, 2004), como:

aquela na qual ele [o conhecimento] poderá ao mesmo tempo chegar a um grande número de pessoas e ser por elas significado através de interações infinitas e pontuais, em redes que se configuram e reconfiguram permanentemente. (MELLO, 2004, p. 146).

A escola do século XXI, da qual se exige a aprendizagem pelo uso da tecnologia, que se depara com o desafio de criar "comunidades inteligentes" e se tornar a "incubadora dos coletivos inteligentes" (MELLO, 2004, p. 149-150), tem, nas políticas educacionais, o aporte necessário à articulação do desafio posto pela agenda do capital.

A "invenção de novos saberes pedagógicos" (MELLO, p. 152) para preparar os profissionais para a execução desse projeto está legalmente assegurada desde as décadas finais do século passado, quando se inicia uma profunda reorganização do Estado e das instituições escolares ${ }^{12}$. Nesse contexto, a educação a distância (EaD) se afirma como um novo paradigma para a educação brasileira. Com o apoio de universidades públicas, centros de pesquisas, agências de fomento, dentre outras, a modalidade $\mathrm{EaD}$ ascende como mercadoria valiosa a ser explorada por empresas, organizações não-governamentais e ser consumida por todos. O suporte acadêmico-institucional das Instituições de Ensino Superior (IES) garante não somente a disseminação da $\mathrm{EaD}$, mas mobiliza o interesse político pela modalidade, haja vista o aporte financeiro garantido às novas adesões.

A consolidação da reforma ganha especial reforço com a estratégia do Estado de fomentar a preparação de recursos humanos com uma política de formação de professores por meio da EaD que ganha contornos mais expressivos com a criação da Universidade Aberta do

${ }^{12}$ Como principal eixo de sustentação jurídica da reforma educacional, citamos a LDB nº 9.394/1996.

\begin{tabular}{|l|l|l|l|l|}
\hline Gonista Dialeatus & Ano 4 & n. 10 & Janeiro - Julho 2017 & p. 115-126 \\
\hline
\end{tabular}


Brasil (UAB) ${ }^{13}$, cujo objetivo é exatamente defender "um sistema voltado para o desenvolvimento da modalidade de educação a distância, com a finalidade de expandir e interiorizar a oferta de cursos e programas de educação superior no país". Outro importante marco de análise é o Plano Nacional de Educação (PNE), período 2001-2010 ${ }^{14}$, que estabelece vinte e dois objetivos e metas a serem implantados ao longo de dez anos para que se atinjam os resultados esperados pelo uso das novas tecnologias de informação e comunicação como ferramenta de apoio ao processo de ensino-aprendizagem. A influência de tal projeto é impactante e está em pleno curso na organização dos sistemas de ensino, no ensino superior e suas licenciaturas.

O crescimento da oferta de matrículas nos cursos de formação inicial de professores em todas as regiões do país é expressivo e representa boa parte do crescimento do ensino superior no país. De acordo com os dados do Censo da Educação Superior 2014 (MEC/INEP, 2014), o número de alunos nas licenciaturas à distância continua crescendo, com 1,34 milhões de matrículas no ano de 2014. Os números representam uma participação de $17,1 \%$ do total de matrículas na educação superior, ou seja, as matrículas na modalidade tiveram o maior crescimento percentual registrado nas universidades. Se comparado com o ano de 2013, o número de ingressos cresceu $41,2 \%$, enquanto que nos cursos presenciais o aumento foi somente de 7,0\%. Além da expansão, o estudo também indica a tendência de concentração das matrículas nos cursos de licenciatura, na rede privada de ensino. (MEC, 2014, p. 7). Essa acentuada presença do capital privado na oferta de $\mathrm{EaD}$ fortalece o processo de transformação da educação, de bem social à forma mercadoria. $\mathrm{O}$ crescimento do setor empresarial na educação brasileira consolida um próspero mercado, cuja faceta mais evidente revela a penetração dos fundos financeiros na educação superior no país, a emissão de ações de instituições de ensino na bolsa de valores e a tendência do que se chama de "oligopolização" da oferta ${ }^{15}$. (OLIVEIRA, 2009).

13 _. Presidência da República. Decreto $\mathbf{n}^{\mathbf{0}} \mathbf{5 . 8 0 0}$, de 8 de junho de 2006. Dispõe sobre o Sistema Universidade Aberta do Brasil - UAB.

${ }^{14}$ BRASIL. Lei $\mathbf{n}^{\circ}$ 10.172, de 09/01/2001. Aprova o Plano Nacional de Educação e dá outras providências.

${ }^{15}$ Oliveira (2009) realiza estudo no qual destaca as transações comerciais realizadas pelo ensino superior privado no Brasil, cada vez mais liberto das restrições e barreiras regulatórias que até então limitavam seu campo de ação. O autor destaca os dados divulgados pela revista Exame, em 22/12/2008, que estima a movimentação anual do ensino privado no país em torno de 90 bilhões de reais, o equivalente a $3 \%$ do nosso PIB. Entre os anos de 2001 a 2008, o setor de ensino privado aumentou seu movimento de capitais de 10 para 90 bilhões de reais, crescimento que nenhum setor da economia brasileira pode comemorar no período. Cf. OLIVEIRA, Romualdo Portela de. A transformação da educação em mercadoria no Brasil. Educ. Soc. [online]. 2009, vol.30, n.108, p. 739-760.

\begin{tabular}{|l|l|l|l|l|}
\hline Q Poxista Qialectus & Ano 4 & n. 10 & Janeiro - Julho 2017 & p. 115-126 \\
\hline
\end{tabular}


Há, além disso, números indícios de que a multiplicação de consórcios e pólos para a oferta de cursos de licenciatura à distância estaria ocorrendo sem que um projeto político-pedagógico de formação docente mais adensado no âmbito de sua articulação nacional e local tenha sido desenvolvido e compartilhado e sem que as estruturas operacionais básicas estejam funcionando adequadamente. (GATTI, BARRETO, 2009, p. 113).

Os estudos oficiais não revelam, contudo, a efetividade da $\mathrm{EaD}$ na aquisição dos conhecimentos necessários à participação qualitativa dos sujeitos na sua própria realidade, assim como não dão ênfase ao debate crítico acerca dos impactos e desafios demandados por essa expansão anômala. Entendo que cabe maior discussão e investigação sobre o que vem se processando na educação brasileira, em todos os seus níveis e modalidades, haja vista as "brechas" sociais reservadas à contradição se mostrarem cada vez mais cooptadas pela razão mercantil que domina a subjetividade dos indivíduos, acentuando as desigualdades, não obstante as promessas da chamada igualdade de oportunidades. Ademais, o fetiche que envolve a EaD traz impactos de longo alcance para a formação e trabalho docentes e para a consolidação de sua identidade, fatores cruciais à construção do sujeito crítico e participativo.

\section{Referências}

BRASIL. Plano decenal de educação para todos.- Brasília: MEC, 1993.

BRASIL. INEP. Censo da Educação Superior 2014: notas estatísticas. [online]. Brasília. Disponível em: <http://download.inep.gov.br/educacao_superior/censo_superior/documentos/2015/notas_sob re_o_censo_da_educacao_superior_2014.pdf> Acesso em: fev de 2016.

BRASIL. Lei $\mathbf{n}^{\circ}$ 10.172, de 09/01/2001. Aprova o Plano Nacional de Educação e dá outras providências.

DUARTE, Newton. Sociedade do conhecimento ou sociedade das ilusões?: quatro ensaios crítico-dialéticos em filosofia da educação. Campinas, SP: Autores Associados, 2003.

FRIGOTTO, Gaudêncio. Educação e crise no capitalismo. São Paulo, Cortez, 2003.2003, .

GATTI, Bernadete Angelina, BARRETO, Elba Siqueira de Sá. Professores do Brasil: impasses e desafios. Brasília: UNESCO, 2009. Disponível em: <

http://unesdoc.unesco.org/images/0018/001846/184682por.pdf> Acesso em: jan 2011.

GUIRALDELLI JR, Paulo. História da educação. 2. ed. São Paulo: Cortez, 1992, p.18.

\begin{tabular}{|l|l|l|l|l|}
\hline Q Povista Qialectus & Ano 4 & n. 10 & Janeiro - Julho 2017 & p. 115-126 \\
\hline
\end{tabular}


LEHER, Roberto. Um novo senhor da educação? a política educacional do Banco Mundial para a periferia do capitalismo. Revista Outubro, p. 19-30, 1999.

LYOTARD, Jean-François. A condição pós-moderna. Tradução de Ricardo Corrêa Barbosa. 12. ed. Rio de Janeiro: José Olympio, 2009.

MARTINS, Lígia Márcia, DUARTE, Newton (orgs). Formação de professores: limites contemporâneos e alternativas necessárias [online]. São Paulo: Editora UNESP; São Paulo: Cultura Acadêmica, 2010. Disponível em: <http://books.scielo.org/id/ysnm8/pdf/martins9788579831034-03.pdf> Acesso em: fev. 2015.

MELLO, Guiomar Namo de. Educação escolar brasileira: o que trouxemos do século XX?. Porto Alegre: Artmed, 2004.

MÉSZÁROS, István. A crise estrutural do capital. São Paulo: Boitempo Editorial. 2009a.

Para além do capital. Tradução Paulo Cezar Castanheira at. al. São Paulo: Boitempo Editorial. 2009b.

NEVES, Lúcia Maria Wanderley (org). A nova pedagogia da hegemonia: estratégias do capital para educar o consenso. São Paulo: Xamã, 2005.

OLIVEIRA, Romualdo Portela de. A transformação da educação em mercadoria no Brasil. Educ. Soc. [online]. 2009, vol.30, n.108, pp. 739-760.

SAVANI, Dermeval. A nova lei da educação: trajetória, limites e perspectivas. 4. ed. Campinas, SP: Autores Associados, 1998.

Formação de Professores: aspectos históricos e teóricos do problema no contexto brasileiro. Rev. Bras. Educ. [online]. 2009, vol.14, n.40, pp. 143-155. Disponível em: < http://www.scielo.br/pdf/rbedu/v14n40/v14n40a12.pdf> Acesso em: 21/04/2009.

A pedagogia no Brasil: história e teoria. Campinas, SP: Autores Associados, 2008.

SOUSA, Dileno D.L. de; SILVA JÚNIOR, João dos Reis; FLORESTA, Ma. Das Graças S. Educação a distância. Diferentes abordagens críticas. São Paulo, Xamã, 2010.

TARDIF, Maurice. Saberes docentes e formação profissional. Petrópolis, RJ: Vozes, 2002.

UNESCO. Declaração Mundial Sobre educação para todos: satisfação das necessidades básicas de aprendizagem. Jomtien, Tailândia, 1990.

\begin{tabular}{|c|c|c|c|c|}
\hline QRovista Dialectus & Ano 4 & n. 10 & Janeiro - Julho 2017 & p. $115-126$ \\
\hline
\end{tabular}

